\title{
Effect of Larval Swimming Duration on Success of Metamorphosis and Size of the Ancestrular Lophophore in Bugula neritina (Bryozoa)
}

\author{
DEAN E. WENDT \\ Department of Organismic and Evolutionary Biology, Harvard University, \\ Cambridge, Massachusetts 02138
}

\begin{abstract}
There is a growing realization that events during one portion of an organism's life cycle can have both subtle and dramatic effects on other stages in the life history. Lethal and sublethal effects associated with the duration of larval swimming in marine invertebrates were examined for the bryozoan Bugula neritina. Larvae were kept swimming up to a maximum of $28 \mathrm{~h}$ at $20^{\circ} \mathrm{C}$ by exposure to continuous bright fluorescent illumination. At 4-h intervals, samples of 20-40 larvae were removed from bright illumination and were exposed to seawater containing $10 \mathrm{mM}$ excess $\mathrm{KCl}$, an inducer of metamorphosis in this species. Over the first $12 \mathrm{~h}$ of larval swimming, an average of about $90 \%$ of the larvae initiated and completed metamorphosis; at $16 \mathrm{~h}$, the percentage of larvae initiating and completing metamorphosis dropped significantly. By $28 \mathrm{~h}$, about half of the larvae were initiating metamorphosis, whereas only onefifth were completing metamorphosis. Larval swimming duration also significantly affected the duration of metamorphosis. By $30 \mathrm{~h}$ of larval swimming, individuals were taking about $25 \%$ longer to complete metamorphosis. Compared to ancestrulae that developed from larvae that were induced to metamorphose shortly after the onset of swimming, those that swam for greater than $8 \mathrm{~h}$ had significantly smaller lophophores. For example, by $28 \mathrm{~h}$ of larval swimming the ancestrular lophophore decreased in height, surface area, and volume by about $25 \%, 40 \%$ and $55 \%$, respectively. This marked decrease in lophophore size may ultimately affect the ability of juveniles to sequester food, compete for space, and attain reproductive maturity. Thus, increasing the duration of
\end{abstract}

larval swimming affects both metamorphosis and the development of postlarval structures, which may ultimately influence colony fitness.

\section{Introduction}

Many sedentary or sessile marine invertebrates possess a larval stage that on an ecological time scale can function to (1) extend species ranges, (2) connect otherwise geographically separated adult populations, (3) alleviate parent-offspring and intraspecific competition, and (4) facilitate the recolonization of disturbed habitats. The longer a larva spends in the plankton, however, the greater the chance that it will incur a cost due to physiological stress, starvation, predation, and advection away from suitable sites (Thorson, 1950; Rumrill, 1990; Morgan, 1995). Thus, theoretically a trade-off exists between the benefits of dispersal and its attendant costs (see Vance, 1973; Strathmann, 1985, for models examining life history strategies).

Recent evidence suggests that, in addition to lethal effects, there are also sublethal costs associated with duration of the larval swimming stage, especially for species with nonfeeding larvae (reviewed by Pechenik, 1990). Sublethal costs influencing juvenile fitness have yet to be incorporated into models of life-history strategies and have not been rigorously characterized empirically. Presumably any sublethal costs associated with remaining in the plankton are due to effects of larval senescence or depletion of energy reserves to a level at which juveniles have reduced fitness.

Feeding larvae should be buffered against costs related to the depletion of energy stores, because they can re- 
plenish their energy reserves continuously (Highsmith and Emlet, 1986; Pechenik and Eyster, 1989). However, they are unable to extend their lives indefinitely, and eventually they either senesce and die or undergo spontaneous metamorphosis (Pechenik, 1990). Because of the limited energy supply (barring use of dissolved organic material [DOM]), aplanktotrophic larvae, i.e., larvae that do not rely on particulate food, ${ }^{1}$ have more rigid constraints on the amount of time they can spend in the plankton.

A larva is considered to be in an extended swimming period when it is physiologically capable of responding to cues that elicit metamorphosis, but instead continues swimming in the absence of those cues. Marine invertebrates do not possess endogenous clocks that control the duration of the larval period, but instead they metamorphose in response to cues associated with a favorable adult habitat (Scheltema, 1974; Hadfield, 1978; Morse and Morse, 1984; Chia, 1989; Pawlik, 1992). Once competent to metamorphose, a larva can remain in the swimming phase for one of two reasons: (1) it has not encountered a suitable cue to trigger metamorphosis; or (2) it has encountered the cue, but additional factors prevent the normal metamorphic response. An example of the latter situation was provided by Young and Chia (1981). They demonstrated that competent larvae of Bugula pacifica delay metamorphosis in the presence of extracts of a dominant competitor, the compound ascidian Diplosoma macdonaldi. In either case, the benefits associated with remaining in the plankton seem readily apparent: a larva is able to synchronize the onset of metamorphosis with encountering a favorable site. However, the longer a larva is in the plankton the greater its exposure to the potential lethal and sublethal effects of a planktonic existence (Rumrill, 1990; Morgan, 1995).

Because planktotrophic larvae can feed on particulate matter throughout the larval stage, they should not incur substantial sublethal costs; aplanktotrophic larvae, on the other hand, have finite energy reserves, and thus should incur these costs quicker and with more severity.

\footnotetext{
'I propose the term aplanktotrophic to include larvae that are either lecithotrophic, translocational, or adelphophagic. Lecithotrophic larvae acquire nutrients (yolk) during oogenesis; translocational larvae have nutrients transferred to the developing embryo after fertilization; and adelphophagic larvae feed on siblings during encapsulation or brooding. These terms refer to the specific processes by which larvae obtain their energy reserves. The inappropriate synonymy of the terms lecithotrophy and nonfeeding is commonly encountered in the literature. Clearly all nonfeeding larvae are not lecithotrophic. The term aplanktotrophic is a more appropriate general classification for larvae that derive their energy reserves from sources other than the plankton, and it emphasizes the underlying similarity of these larvae (i.e., not feeding on planktonic particulate matter). From an energetic standpoint, aplanktotrophic larvae are independent of particulate food in the plankton.
}

This generalization is supported by the few studies that have addressed the issue explicitly. For example, Highsmith and Emlet (1986) found no significant correlation betwecn delay time and juvenile growth rate in the sand dollar Echinorachnius parma, which has planktotrophic larvae. Also, Pechenik and Eyster (1989) found no significant differences in average survival, feeding, respiration, or growth rates between juveniles of the planktotrophic gastropod Crepidula fornicata that were induced to metamorphose shortly after attaining competence and those that were kept swimming until metamorphosis occurred spontaneously. Results of these two studies suggest that planktotrophic larvae can have an extended larval swimming period without incurring substantial cost to juvenile fitness.

In contrast, species with aplanktotrophic larvae can incur sublethal costs as the duration of the larval swimming period increases. For example, in 12 out of 14 cases Woollacott et al. (1989) demonstrated that after $10 \mathrm{~h}$ of swimming, larvae of $B$. stolonifera developed into juveniles that grew significantly slower than juveniles developed from larvae that had a swimming period of $6 \mathrm{~h}$. For the barnacle Balanus amphitrite, prolonging the swimming period of cyprids for 3-5 days dramatically depressed juvenile growth rate compared to controls (Pechenik et al., 1993). Conversely, Pechenik and Cerulli (1991) found that prolonging the swimming period of the aplanktotrophic larvae of the marine polychaete $\mathrm{Ca}$ pitella sp. I for up to $216 \mathrm{~h}$ had no effect on postmetamorphic growth rate, time to first reproductive activity, or fecundity. However, increasing larval swimming time did significantly decrease postsettlement survivorship from $100 \%$ (not prolonged) to $12.5 \%$ (prolonged for $216 \mathrm{~h}$ ). Although those individuals that survived incurred no sublethal costs, there was a substantial postlarval mortality.

Clearly, being able to initiate and to complete metamorphosis is central to survival. More subtle, however, are the sublethal effects associated with a prolonged period of larval swimming. Intra- and interspecific competition between sessile invertebrates for space and food is directly related to size (Buss, 1979; Buss and Jackson, 1981). In addition, for Bugula neritina, reproductive maturity is attained only after a minimum number of bifurcations (Keough, 1987). Therefore, an individual's fitness may be compromised by being smaller after metamorphosis or by taking longer to metamorphose.

The effects of the duration of larval swimming were assessed for the cheilostome bryozoan $B$. neritina, which has an aplanktotrophic larva that acquires its nutrient reserves translocationally through a placenta-like system (Woolacott and Zimmer, 1975). Specifically, I examined (1) duration of metamorphosis; (2) ability of larvae to initiate metamorphosis; (3) ability of individuals to com- 
plete metamorphosis; and (4) size of and tentacles in the ancestrular lophophore. Because larvac of $B$. neritina arc aplanktotrophic and therefore limited energetically, I predicted (1) a positive correlation between larval swimming duration and time required to complete metamorphosis (a result of the utilization of less labile energy sources to complete metamorphosis); (2) an inverse correlation between larval swimming duration and ability to initiate and complete metamorphosis; and (3) a negative correlation between size of the lophophore and duration of the larval swimming stage. These factors influence the ability to sequester food, compete for space, and attain reproductive maturity, which undoubtedly affects an individual's fitness.

\section{Materials and Methods}

Gravid colonies of Bugula neritina were collected from the undersides of floating docks near the Smithsonian Marine Station in Fort Pierce, Florida, from February through April 1995 and in February 1996. Colonies were shipped to Cambridge, Massachusetts, and were maintained in the laboratory in plastic aquaria at $20^{\circ} \mathrm{C}$ in darkness with continuous aeration. No food was provided for the colonies.

Larvae were obtained from pools of colonies to foster genetically heterogeneous populations for the experiments. Colonies were removed from the dark, placed in glass bowls with $1.5 \mathrm{l}$ of seawater, and exposed to fluorescent light. Within 30 min of illumination, larvae appeared; by 2 h, release was complete. $B$. neritina larvae are positively phototactic on release, and this behavior facilitated their collection because they aggregated on the illuminated side of dishes. Larvae were collected and dispensed to experimental vessels with pipettes. Experiments were started within $1.5 \mathrm{~h}$ after the appearance of larvae; therefore, at most, larvae would differ in age by 90 min. Larvae used in experiments were obtained only from parent colonies kept in the laboratory less than 6 days, and parent colonies were re-used for releases over this 5-day period in the laboratory.

Larvae of $B$. neritina did not initiate metamorphosis when exposed to bright fluorescent illumination; thus by removing larvae from the illumination at regular intervals, it was possible to create populations that differed in the length of swimming time. Following release, larvae were transferred to a glass finger bowl containing $250 \mathrm{ml}$ of $0.2-\mu \mathrm{m}$-filtered seawater. The finger bowl was illuminated from below using three 50 -watt fluorescent Vita Lites. Illumination levels ranged from 130 to $145 \mu \mathrm{E}$ $\mathrm{m}^{-2} \mathrm{~s}^{-1}$. Due to their small size, the larvae in each condition could only be counted accurately after the experiment was over. Approximately 20-40 larvae were removed from the bright fluorescent illumination at $4-\mathrm{h}$ intervals for $28 \mathrm{~h}$. They were then pipetted into glass Stendor dishes containing $20 \mathrm{ml}$ of $0.2-\mu \mathrm{m}$-filtered scawater with an excess of $10 \mathrm{mM} \mathrm{KCl}$, an inducer of bryozoan metamorphosis (Wendt and Woollacott, 1995). The swimming times reported are minimum estimates in that larvae did not initiate metamorphosis instantaneously. However, preliminary experiments showed that $>70 \%$ of the larvae initiated metamorphosis within the first hour after transfer. Initiation and completion of metamorphosis were determined for each sample condition after $72 \mathrm{~h}$ (see below on how initiation and completion are defined).

Each time condition was sampled and metamorphosed individuals were "relaxed" in $7.5 \% \mathrm{MgCl}_{2}$. Tentacle length, lophophore crown diameter, and lophophore base diameter were measured for each ancestrula (Fig. 1). These parameters were used to calculate height, volume, and surface area of the lophophore on the basis of the following equations (Beyer, 1987),

$$
\begin{gathered}
\text { I leight }=\sqrt{c^{2}-(1 / 4)(a-b)^{2}} \\
\text { Volume }=\pi h\left[a^{2}+a b+b^{2}\right] / 12 \\
\text { Surface area }=\pi c(a+b) / 2
\end{gathered}
$$

where $a$ is diameter of the lophophore at its crown, $b$ is

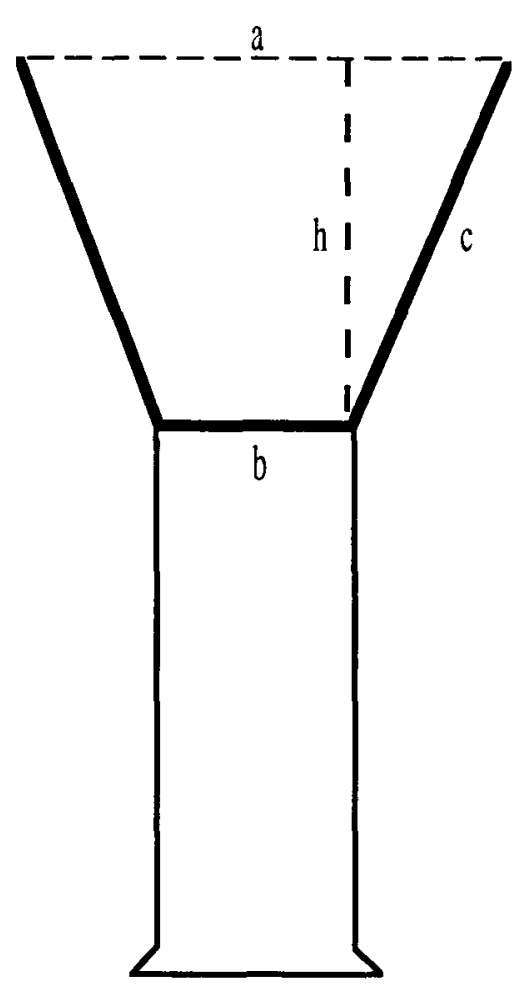

Figure 1. Schematic of an ancestrula of Bugula neritina showing the measured parameters, crown diameter (a), base diameter (b), and tentacle length (c), and the calculated parameter, height $(h)$. The height was calculated using equation 1 in Materials and Methods. 
diameter of the lophophore at its base, $c$ is tentacle length, and $h$ is height of the lophophore.

An additional three trials of this experiment (using 270 individuals) were carried out to extend the larval swimming period by 12 more hours and to increase the number of individuals at later time points. This experiment followed an identical protocol, but larvae were sampled only at $0 \mathrm{~h}, 30 \mathrm{~h}$, and $40 \mathrm{~h}$. Due to the difference in sampling times, data from these three trials are presented separately.

A second experiment was conducted to determine if the time to metamorphosis changed as a function of larval swimming duration. In this experiment larvae were sampled at 10-h intervals, and they were transferred to and kept separate in 2-ml multiwelled dishes. Individual larvae were followed on an hourly basis to provide an accurate determination of when metamorphosis was initiated and completed.

Attachment (often referred to as settlement in the literature) of bryozoan larvae is tightly coupled to metamorphosis in that attachment is not reversible and is marked by eversion of the metasomal (internal) sac. This is the first morphogenetic movement of metamorphosis in larvae of Bugula spp. and other bryozoans (Zimmer and Woollacott 1977). Thus, attachment in bryozoans is not exclusively a behavioral change associated with substratum exploration. I will hereafter refer to this process as the initiation of metamorphosis. Metamorphosis was considered complete after the ancestrula everted its lophophore.

The number of larvae that initiated and completed metamorphosis in each treatment was expressed as a percentage. The results of each of the replicates were plotted individually to determine between-trial similarity. Without exception, the general trends were similar in each of the replicates, and the replicates were thus treated as single data sets for statistical analysis and graphing. Data from within treatments did not differ significantly from a normal distribution, so a factorial ANOVA was performed to identify heterogeneity of variances within the data set. Fisher's protected least significant difference (PLSD), a post hoc test, was used to identify sources of such variation among the data.

\section{Results}

\section{Duration of metamorphosis}

Time required from initiation to completion of metamorphosis increased significantly for each 10 -h increase in larval swimming period (ANOVA, $F=55.7 ; P=$ $<0.0001$ : Fisher PLSD, 0 vs. 10, $P=0.004,10$ vs. 20 and 20 vs. 30, $P=<0.0001$ ). Mean duration of metamorphosis was $39 \pm 0.4 \mathrm{~h}, 42 \pm 0.3 \mathrm{~h}, 46 \pm 0.7 \mathrm{~h}$, and $49 \pm 0.9 \mathrm{~h}$ for individuals that developed from larvae swimming for

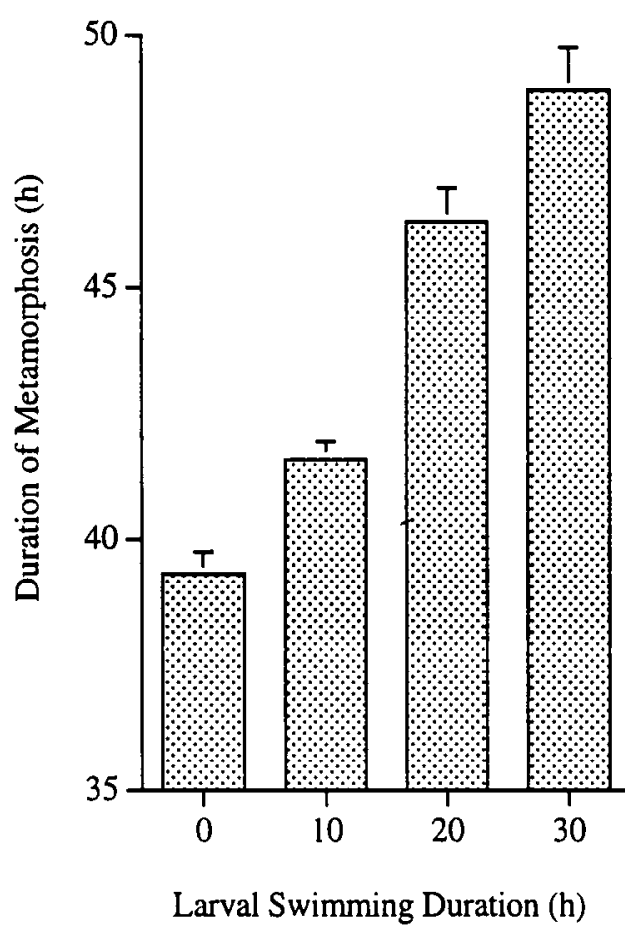

Figure 2. Bugula neritina. Duration of metamorphosis versus larval swimming period. Individual larvae were followed on an hourly basis from initiation (attachment by eversion of the metasomal sac) to completion (eversion of the lophophore) of metamorphosis. All time classes are significantly different from each other (bars $=1$ standard error; $n=26-35$ for each condition).

$0,10,20$, and $30 \mathrm{~h}$, respectively (Fig. 2). Cumulative percent completion of metamorphosis was sigmoidal, although the curve was right-shifted for each successive larval swimming period (Fig. 3). The amount of time for $50 \%$ of the individuals to complete metamorphosis $\left(K_{0}\right)$ was approximately $37.5,40.5,44.0$, and $49.0 \mathrm{~h}$ for individuals that developed from larvae swimming $0,10,20$, and $30 \mathrm{~h}$, respectively (Fig. 3). Duration of metamorphosis ranged from 36 to $62 \mathrm{~h}$.

\section{Initiation and completion of metamorphosis}

An increased larval swimming period significantly affected the percentage of individuals initiating and completing metamorphosis. ANOVA revealed significant heterogeneity of variances for percent initiation and percent completion of metamorphosis over the duration of the experiment (Table I). On average, close to $95 \%$ of the larvae initiated metamorphosis through $12 \mathrm{~h}$ (Fig. 4). At $16 \mathrm{~h}, 67 \pm 7 \%$ (mean \pm standard error) of the larvae were initiating metamorphosis $(P=0.01$; Fisher PLSD). After $16 \mathrm{~h}$ the percentage of larvae initiating metamorphosis decreased slightly, although the variability between trials was such that no significant decline occurred between 16 and $28 \mathrm{~h}$. On average for 0 through $12 \mathrm{~h}$, the percentage 


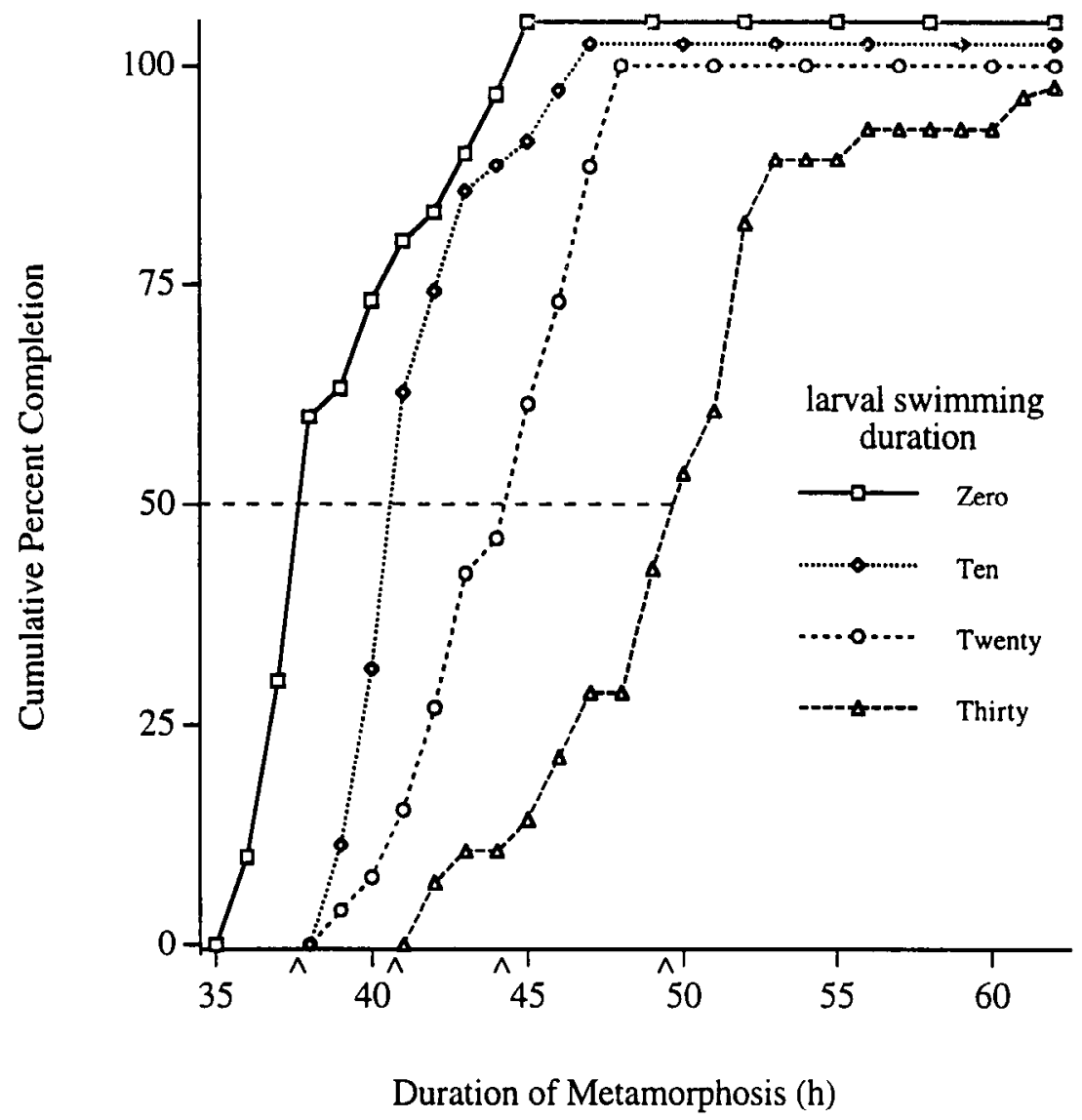

Figure 3. Bugula neritina. Cumulative percent completion of metamorphosis versus larval swimming period. $K_{\mathrm{c}}$ values, the time for $50 \%$ of the individuals to complete metamorphosis, were approximated by connecting $50 \%$ completion to the $x$-axis. Lines at $100 \%$ completion are staggered for clarity. $n=26-35$ individuals for each swimming time.

of individuals completing metamorphosis was almost identical to the number of larvae initiating metamorphosis (Fig. 4). The percentage of individuals completing metamorphosis declined significantly at $16 \mathrm{~h}$ to $52 \% \pm$

\section{Table I}

One-factor ANOVA results for the effect of larval swimming duration on duration of metamorphosis, on initiation and completion of metamorphosis, on the height, surface area, and volume of the lophophore, and on the measured parameters of the lophophore

\begin{tabular}{llcr}
\hline \hline \multicolumn{1}{c}{ Parameter } & df & $F$-test & \multicolumn{1}{c}{$P$-value } \\
\hline Duration of metamorphosis & 3 & 55.75 & $<0.0001$ \\
Initiation of metamorphosis & 7 & 5.97 & 0.0002 \\
Completion of metamorphosis & 7 & 25.63 & $<0.0001$ \\
Tentacle length & 7 & 9.98 & $<0.0001$ \\
Lophophore diameter (top) & 7 & 9.981 & $<0.0001$ \\
Lophophore diameter (base) & 7 & 4.180 & $<0.0003$ \\
Lophophore height & 7 & 9.195 & $<0.0001$ \\
Lophophore surface area & 7 & 10.69 & $<0.0001$ \\
Lophophore volume & 7 & 10.58 & $<0.0001$ \\
\hline
\end{tabular}

$12 \%$ (mean \pm standard error; $P=0.0004$; Fisher PLSD), In contrast to initiation, however, mean percentage of individuals completing metamorphosis declined significantly from $16 \mathrm{~h}$ to 24 and $28 \mathrm{~h}$ (mean \pm standard error, $52 \pm 12,22 \pm 7$, and $17 \pm 3$, respectively: $P=<0.003$; Fisher PLSD).

\section{Lophophore parameters}

An increased larval swimming period significantly affected the size of the ancestrular lophophore in Bugula neritina. Mean tentacle length and base and crown diameters of the lophophore of the ancestrulae decreased by $25 \%, 24 \%$, and $12.5 \%$, respectively, in individuals that developed from larvae that were swimming for $28 \mathrm{~h}$ compared to individuals that developed from larvae induced to metamorphose shortly after the onset of larval swimming (Table II). Mean height, surface area, and volume of the lophophore decreased as a function of increased larval swimming duration (Fig. $5 \mathrm{a}, \mathrm{b}, \mathrm{c}$ ). ANOVA revealed significant heterogeneity of variances for 


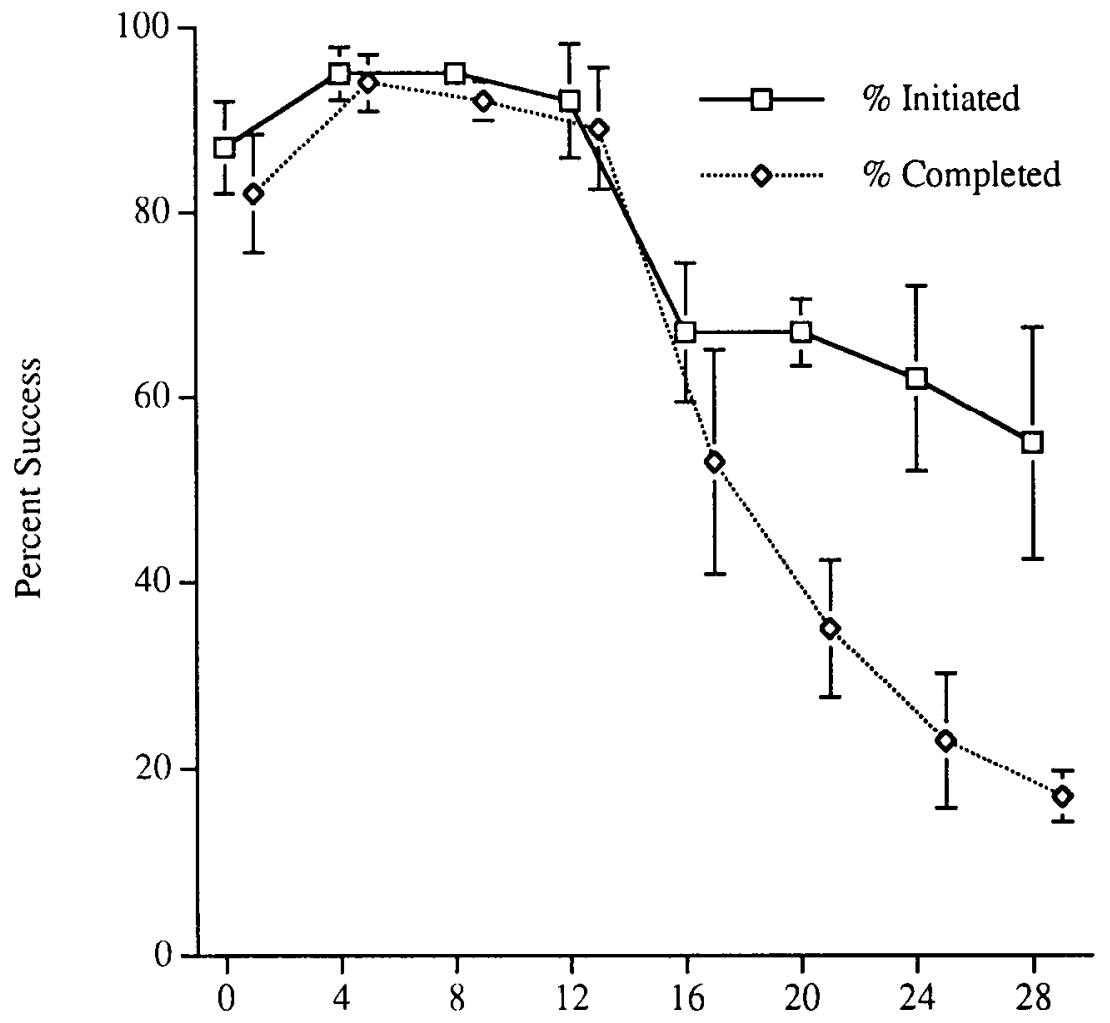

Larval Swimming Duration (h)

Figure 4. Percent initiation and completion of metamorphosis versus larval swimming duration in Bugula nerilina. Larvae kept swimming for $16 \mathrm{~h}$ were less likely to both initiate and complete metamorphosis. The lines are staggered slightly for clarity (bars $=1$ standard error; $n=5$ ).

each of these calculated parameters (Table I), and significant declines occurred after $8 \mathrm{~h}$ of larval swimming. By $28 \mathrm{~h}$ of larval swimming the percent decrease in mean lophophore height, surface area, and volume was $25 \%$, $40 \%$, and $55 \%$, respectively, compared to individuals that developed from larvae induced to metamorphose shortly after the onset of larval swimming. Maximum number of tentacles (21: range 19-21) occurred in indi- viduals that developed from larvae induced to metamorphose shortly after the onset of larval swimming (Table II). Minimum number of tentacles (16: range 16-20) occurred in ancestrulae that developed from larvae kept swimming for $24 \mathrm{~h}$ prior to the onset of metamorphosis (Table II).

Significant declines were observed for all parameters in the second experiment also. After $40 \mathrm{~h}$ of larval swim-

Table II

Tentacle length, top and base diameter of the lophophore, and ranges of tentacle number as a function of larval swimming duration (mean \pm standard error of the mean); measurements were made on ancestrulae less than $24 \mathrm{~h}$ post metamorphosis

\begin{tabular}{cccccc}
\hline \hline Swimming Duration $(\mathrm{h})$ & $N$ & Tentacle Length $(\mu \mathrm{m})$ & Top Diameter $(\mu \mathrm{m})$ & Base Diameter $(\mu \mathrm{m})$ & Tentacle \# $($ Range:Mode $)$ \\
\hline 0 & 28 & $520 \pm 10$ & $556 \pm 10$ & $152 \pm 3$ & $19-21: 20$ \\
4 & 31 & $493 \pm 11$ & $535 \pm 11$ & $153 \pm 2$ & $17-21: 19$ \\
8 & 28 & $467 \pm 13$ & $513 \pm 11$ & $145 \pm 3$ & $18-21: 19$ \\
12 & 32 & $469 \pm 12$ & $518 \pm 9$ & $145 \pm 2$ & $17-21: 20$ \\
16 & 23 & $442 \pm 12$ & $499 \pm 13$ & $139 \pm 4$ & $17-21: 19$ \\
20 & 23 & $412 \pm 16$ & $474 \pm 20$ & $142 \pm 3$ & $17-21: 19$ \\
24 & 15 & $400 \pm 16$ & $424 \pm 15$ & $133 \pm 4$ & $18-20: 18,19$ \\
28 & 8 & $390 \pm 27$ & $423 \pm 21$ & & \\
\hline
\end{tabular}



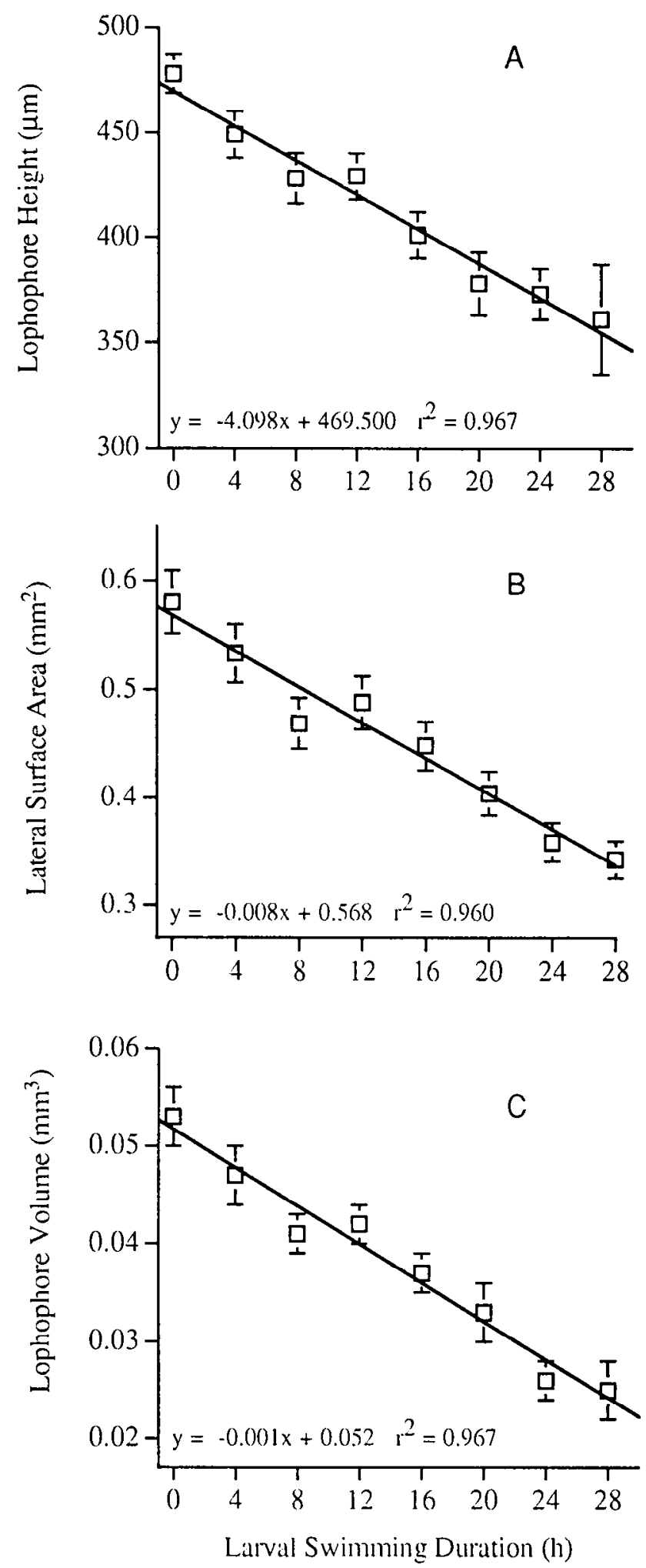

Figure 5. Bugula neritina. Height (A), surface area (B), and volume (C) of lophophore as a function of larval swimming duration in Bugula neritina. Samples of larvae were taken every $4 \mathrm{~h}$, at which time they wcre induced to metamorphose by exposure to $10 \mathrm{mM}$ excess $\mathrm{KCl}$ in seawater. Each datum is the mean of 8-32 individuals pooled from 5 replicates (bars $=1$ standard error). ming, the mean height, surface area, and volume decreased by $c a$. $30 \%, 50 \%$, and $62 \%$, respectively, when compared to those of individuals that developed from larvae induced to metamorphose shortly after the onset of larval swimming (ANOVA; $F=>100.00, P=$ $<0.0001$ for each parameter; $n=3$; a total of 107,143 , and 20 individuals were measured for 0,30 , and $40 \mathrm{~h}$, respectively).

\section{Discussion}

\section{Duration of metamorphosis}

Duration of metamorphosis on average increased as a function of larval swimming period (Figs. 2 and 3). After $30 \mathrm{~h}$ of larval swimming, individuals were taking almost $10 \mathrm{~h}$ longer to complete metamorphosis than those induced shortly after the onset of larval swimming. The observed increase in duration of metamorphosis is probably due to the utilization of less labile energy sources to complete metamorphosis. In Bugula spp. certain larval tissues (e.g., the corona, ciliated epithelia, and vesicular collarettes) are transitory. At the onset of metamorphosis these tissues are internalized and ultimately undergo histolysis (Woollacott and Zimmer, 1978). Individuals that swim longer before initiating metamorphosis deplete labile energy stores to a greater degree and, therefore, they must rely more heavily on these transitory tissues for the energy necessary to complete metamorphosis. It is likely that the biochemical processes needed to histolyze these tissues increase the duration of metamorphosis. Whether the increase in duration of metamorphosis compromises juvenile fitness has yet to be determined.

\section{Initiation and completion of metamorphosis: lethal effects and the mechanisms governing abilities to initiate and complete metamorphosis}

These data document a substantial lethal cost to $B$. neritina in that a significant portion of larvae lose the ability over time to initiate or complete metamorphosis. Woollacott et al. (1989) found similar lethal costs in $B$. stolonifera in that $40 \%$ of larvae lost metamorphic competence after $10 \mathrm{~h}$ of swimming. A loss of competence was also observed after $24 \mathrm{~h}$ of larval swimming in $\mathrm{Cel}$ leporella hyalina, another cheilostome bryozoan (Orellana and Cancino, 1991). Pechenik and Cerulli (1991) found that delaying metamorphosis of the aplanktotrophic larvae of the marine polychaete Capitella sp. caused an $87 \%$ decrease in postsettlement survivorship in individuals that developed from larvae that were swimming for $216 \mathrm{~h}$, compared to individuals that developed from larvae induced to metamorphose shortly after becoming competent.

The mechanisms governing the ability of larvae to ini- 
tiate metamorphosis and the ability of larvae to complete metamorphosis are unknown. Two hypotheses have been presented to explain loss of metamorphic competence: (1) an energetic hypothesis stating that larvae lose competence as a result of depleting energy reserves during swimming (Lucas et al., 1979; Pechenik, 1990; Jaeckle, 1994; Pawlik and Mense, 1994); and (2) a sensory hypothesis stating that larvae are unable to respond to cues due to degradation of the receptor or other limiting elements in the transduction pathway (Pechenik, 1980; Pechenik and Fried, 1995). These processes are probably not mutually exclusive given that the ability of larvae to maintain a functional receptoral apparatus is also presumably dependent on energy.

The ability of $B$. neritina to successfully initiate metamorphosis may not depend directly on depletion of energetic reserves. If ability to initiate metamorphosis were under energetic constraints, then as larvae continue to swim, one might expect a larger portion to deplete their reserves below the level needed for initiating metamorphosis. One should then observe a continuous decrease in successful initiation throughout the duration of larval swimming. Such a pattern, however, was not observed. Specifically, after $16 \mathrm{~h}$ of larval swimming, the ability to initiate metamorphosis was not negatively correlated with larval swimming duration (Fig. 4). Further data for addressing energetic constraints as an explanation for loss of metamorphic competence (i.e., ability to initiate) in $B$. neritina is provided by Jaeckle (1994) in his respirometry work with larvae. If we assume an average respiration rate of $0.118 \mathrm{~mJ} \mathrm{larva}^{-1} \mathrm{~h}^{-1}$ (calculated from data in table 5; Jaeckle, 1994) and an average energy content of $15.24 \mathrm{~mJ} \mathrm{larva}^{-1}$ for larvae of $B$. neritina (Jaeckle, 1994), by $16 \mathrm{~h}$ of swimming, larvae will have depleted $12 \%$ of their energy content. Whether a $12 \%$ decrease in larval energy reserves is sufficient to cause a loss of metamorphic competence is unknown, but on average over $60 \%$ of larvae retained metamorphic competence at this time. These data suggest that an alternative mechanism (e.g., receptor degeneration) may be governing the loss of metamorphic competence in B. neritina.

Although the ability to initiate metamorphosis may not be under energetic control, the ability to complete metamorphosis is likely to be constrained energetically. The fact that completion of metamorphosis continues to decrease significantly throughout the duration of larval swimming indicates that energetic limitations exist. The exact portion of individuals that initiate but fail to complete metamorphosis is represented by the divergence of the two curves after $16 \mathrm{~h}$ (Fig. 4). On average by $28 \mathrm{~h}$ of larval swimming, only $30 \%$ of the individuals that initiated metamorphosis successfully completed it. The divergence between the ability of larvae to initiate and complete metamorphosis after $12 \mathrm{~h}$ demonstrates that although larvae can successfully respond to cues and initiate metamorphosis, they are unable to complete it (Fig. 4). This observation suggests that factors controlling the ability to initiate metamorphosis are distinct from those controlling the ability to complete it. Possibly, as the population of larvae continue swimming, a larger portion deplete their energy reserves beyond the amount needed to complete metamorphosis. This energetic dependency is further supported by the observation that larvae die at various stages during metamorphosis.

Thus, for aplanktotrophic bryozoan larvae, ability to initiate metamorphosis appears independent of energy reserves and may depend on degradation of some key element in the receptor pathway responsible for site recognition. In contrast, ability to complete metamorphosis may depend on larval energy reserves and, therefore, indirectly on the duration of the larval swimming period.

In light of recent studies on the uptake of dissolved organic matter (DOM) in invertebrate larvae (Langdon, 1983; Manahan, 1983, 1989, 1990; Jaeckle and Manahan, 1989a, b; Shilling and Manahan, 1990; Welborn and Manahan, 1990; Ronnestad et al. 1992; Fenaux et al., 1994; Hoegh-Guldberg, 1994; Jaeckle, 1994, 1995b), discussions of larval energetics must incorporate the potential metabolic contributions of this alternative energy source. It should be emphasized, however, that although the transport of DOM by larvae is well established, the metabolic use of this additional energy pool and its relevance to larval ecology remain equivocal (Pechenik, 1990; Jaeckle, 1995a). Experiments are needed that compare metamorphic competence, maximum swimming duration, and size after metamorphosis between individuals that have access to DOM and those that do not.

\section{Lophophore parameters: sublethal effects and their potential costs to juvenile fitness}

In addition to the lethal costs, such as the loss of metamorphic competence and the inability of larvae to complete metamorphosis, there exist more subtle, sublethal costs to juvenile fitness. These results document that mean size of the ancestrular lophophore decreases as larval swimming period increases (Table II, Figs. 5a, b, c). After a larval swimming period of $28 \mathrm{~h}$, there were significant reductions in all parameters of the lophophore. Sublethal costs to juvenile fitness have also been demonstrated for the congener B. stolonifera (Woollacott $e t$ al., 1989) and the barnacle Balanus amphitrite (Pechenik et al., 1993). The observed reduction in lophophore size may affect the ability of ancestrulae to clear food particles from their surrounding medium. The surface area and volume of the lophophore have not been examined explicitly as variables in bryozoan feeding rates, although 
the height of the lophophore has been shown to be positively correlated with particle velocity (Best and Thorpe, 1986). The observed decrease in height (Fig. 5a) may have a marked effect on competitive ability of ancestrulae, because larvae commonly recruit in a clumped fashion (Keough, 1984; Roberts et al., 1991). Furthermore, Keough (1987) found that postmetamorphic mortality of Bugula neritina is as high as $70 \%$ within the first week. He attributed this high mortality rate to microhabitat differences, but further evaluation in the context of postmetamorphic conspecific competition is needed. Also, becausc reproduction in $B$. neritina occurs only after a colony reaches a certain minimum size ( $c a$. 7 bifurcations) and total reproductive output in colonial marine organisms is a function of overall colony size (Keough, 1989), individuals with a greater ability to gather food will attain the reproductive threshold sooner. My results demonstrate that increasing the duration of larval swimming in the aplanktotrophic larvae of $B$. neritina causes a marked decrease in lophophore size, which may ultimately compromise colony fitness.

This study clearly demonstrates the effects of extended larval swimming on the metamorphosis and development of postlarval structures in marine invertebrates. The lethal and sublethal effects accrued to individuals as a result of events that occur during the larval period have also been shown in fish (McCormick and Molony, 1992) and amphibians (Audo et al., 1995). Understanding the scope of these effects in marine invertebrates as well as fish and amphibians will require studies of the physiological underpinnings of these effects and the costs to juvenile fitness.

\section{Acknowledgments}

I thank Sherry Reed at the Smithsonian Marine Station at Link Port, Fort Pierce, Florida, for generously collecting all the animals used in these experiments. Colleen Cavanaugh, Edward Seling, Michael Temkin, and Robert Woollacott (all of Harvard University) provided thoughtful discussions and comments. Jan Pechenik (Tufts University) and an anonymous reviewer offered valuable comments and criticisms that greatly improved this paper.

\section{Literature Cited}

Audo, M. C., T. M. Mann, T. I. Polk, C. M. Loudenslager, W. J. Diehl, and R. Altig. 1995. Food deprivation during different periods of tadpole (Hyla chrysoscelis) ontogeny affects metamorphic performance differently. Oecologica 103: 518-522.

Best, M. A., and J. A. Thorpe. 1986. Feeding-current interaction and competition for food among the bryozoan epiphytes of Fucus serratus. Mar. Biol. 93: 371-375.

Beyer, W. H. ed. 1987. CRC Handbook of Mathematical Sciences. CRC Press, Boca Raton, FL. Pp. 160-161.
Buss, L. W. 1979. Bryozoan overgrowth interaction-the interdependence of competition for space and food. Nature 281: 475-477.

Buss, L. W., and J. B. C. Jackson. 1981. Planktonic food availability and suspension-feeder abundance: evidence of in situ depletion. $J$. Exp. Mar. Biol. Ecol. 49: 151-161.

Chia, F.-S. 1989. Differential larval settlement of benthic marine invertebrates. Pp. 3-12 in Reproduction, Genetics, and Distribution of Marine Organisms, J. S. Ryland and P. A Tyler, eds. Olsen \& Olsen, Denmark.

Fenaux, L., M. F. Strathmann, and R. R. Strathmann. 1994. Five tests of food-limited growth of larvae in coastal waters by comparisons of rates of development and form of echinopleutei. Limnol. Oceanog. 39 89-94.

Hadfield, M. G. 1978. Metamorphosis in marine molluscan larvae: an analysis of stimulus and response. Pp 165-175 in Settlement and Metamorphosis of Marine Invertebrate Larvae, F.-S. Chia and M. E. Rice, eds. Elsevier North-Holland, New York.

Highsmith, R. C., and R. B. Emlet. 1986. Delayed metamorphosis: effect on growth and survival of juvenile sand dollars (Echinoidea: Clypeasteroida). Bull. Mar. Sci. 39: 347-361.

Hoegh-Guldberg, O. 1994. Uptake of dissolved organic matter by larval stage of the crown-of-thorn starfish Acanthaster planci. Mar. Biol. 120: 55-63.

Jaeckle, W. B. 1994. Rates of energy consumption and acquisition by lecithotrophic larvae of Bugula neritina (Bryozoa: Cheilostomata). Mar. Biol. 119: 517-523.

Jaeckle, W. B. 1995a. Variation in the size, energy content, and biochemical composition of invertebrate eggs: correlates to the mode of larval development. Pp. 49-78 in Ecology of Marine Invertebrate Larvae, L. R. McEdward, ed. CRC Press, Boca Raton, FL.

Jaeckle, W. B. 1995b. Transport and metabolism of alanine and palmitic acid by field-collected larvae of Tedania ignis (Porifera, Demospongiae): estimated consequences of limited label translocation. Biol. Bull. 189: 159-167.

Jaeckle, W. B., and D. T. Manahan. 1989a. Amino acid uptake and metabolism by larvae of the marine worm Urechis caupo (Echiura), a new species in axenic culture. Biol. Bull. 176: 317-326.

Jaeckle, W. B., and D. T. Manahan. 1989b. Feeding by a "nonfeeding" larva: uptake of dissolved amino acids from seawater by lecithotrophic larvae of the gastropod Haliotis rufescens. Mar. Biol. 103: 87-89.

Keough, M. J. 1984. Kin-recognition and the spatial distribution of larvae of the bryozoan Bugula neritina. Evolution 38: 142-147.

Keough, M. J. 1987. Dispersal and population variation in the bryozoan Bugula neritina. Ecology 68: 199-210.

Keough, M. J. 1989. Variation in growth rate and reproduction of the bryozoan Bugula neritina. Biol. Bull. 177: 277-286.

Langdon, C. J. 1983. Growth studies with bacteria-free oyster (Crassostrea gigas) larvac fed on semi-defined artificial diets. Biol. Bull. 164: $227-235$.

Lucas, M. I., G. Walker, D. L. Holland, and D. J. Crisp. 1979. An energy budget for the free-swimming and metamorphosing larva of Balanus balanoides (Crustacea: Cirripedia). Mar. Biol. 55: 221229.

Manahan, D. T. 1983. The uptake and metabolism of dissolved amino acids by bivalve larvae. Biol. Bull. 164: 236-250.

Manahan, D. T. 1989. Amino acid fluxes to and from seawater in axenic veliger larvae of a bivalve (Crassostrea gigas). Mar. Ecol. Prog. Ser. 53: 247-255.

Manahan, D. T. 1990. Adaptations by invertebrate larvae for nutrient acquisition from seawater. Am. Zool. 30: 147-60.

McCormick, M. I., and B. W. Molony. 1992. Effects of feeding history on the growth characteristics of a reef fish at settlement. Mar. Biol. 114: 165-173. 
Morgan, S. G. 1995. Life and death in the plankton: larval mortality and adaptation. Pp. 279-321 in Ecology of Marine Invertebrate Larvae, L. R. McEdward, ed. CRC Press, Boca Raton, FL.

Morse, A. N. C., and D. E. Morse. 1984. Recruitment and metamorphosis of Haliotis larvae induced by molecules uniquely available at the surfaces of crustose red algae. J. Exp. Mar. Biol. Ecol. 75: 191-215.

Orellena, M. R., and J. M. Cancino. 1991. The effects of delaying larval settlement on metamorphosis and early colonial growth in Celleporella hyalina (Bryozoa: Cheilostomata). Pp. 309-316 in Bryozou Living and Fossil, F. P. Bigley, ed. Bull. Soc. Sci. Nat. Quest. Fr., Mém. HSl., Saint-Herblain, Nantes.

Pawlik, J. R. 1992. Chemical ecology of marine invertebrates. Oceanogr. Mar. Biol. Annu. Rev. 30: 273-335.

Pawlik, J. R., and D. J. Mense. 1994. Larval transport, food limitation, ontogenetic plasticity, and the recruitment of sabellariid polychaetes. Pp. 275-286 in Reproduction and Development of Marine Invertebrates, W. H. Wilson, S. A. Stricker, and G. L. Shinn, eds. Johns Hopkins University Press, Baltimore.

Pechenik, J. A. 1980. Growth and energy balance during the larval lives of three prosobranch gastropods. J. Exp. Mar. Biol. Ecol. 44: $1-28$.

Pechenik, J. A. 1990. Delayed metamorphosis of benthic marine invertebrates: Does it occur? Is there a price to pay? Ophelia 32: 6394.

Pechenik, J. A., and T. R. Cerulli. 1991. Influence of delayed metamorphosis on survival, growth, and reproduction of the polychaete Capitella sp. I. J. Exp. Mar. Biol. Ecol. 151: 17-27.

Pechenik, J. A., and L. S. Eyster. 1989. Influence of delayed metamorphosis on the growth and metabolism of young Crepidula fornicata (Gastropoda) juveniles. Biol. Bull. 176: 14-24.

Pechenik, J. A., and B. Fried. 1995. Effect of temperature on survival and infectivity of Echinostoma trivolvis cercariae: a test of the energy limitation hypothesis. Parisitology 111 : 373-378.

Pechenik, J. A., D. Rittschof, and A. R. Schmidt. 1993. Influence of delayed metamorphosis on survival and growth of juvenile harnacles Balanus amphitrite. Mar. Biol. 115: 287-294.

Roberts, D., D. Rittschof, E. Holm, and A. R. Schmidt. 1991. Factors influencing initial larval settlement: temporal, spatial and surface molecular components. J. Exp. Mar. Biol. Ecol. 150: 203-211.

Ronnestad, I., H. J. Fyhn, and K. Gravningen. 1992. The importance of free amino acids to the energy metabolism of eggs and larvae of turbot (Scophthalmus maximus). Mar. Biol. 114: 517-525.

Rumrill, S. S. 1990. Natural mortality of marine invertebrate larvae. Ophelia 32: 163-198.

Scheltema, R.S. 1974. Biological interactions determining larval settlement of marine invertebrates. Thalassia Jugos. 10: 263-296.

Shilling, F. M., and D. T. Manahan. 1990 . Energetics of early marine development for the sea urchins Strongylocentrotus purpuratus and Lytechinus pictus and the crustacean Artemia sp. Mar. Biol. 106: 119-128.

Strathmann, R. R. 1985. Feeding and nonfeeding larval development and life-history evolution in marine invertebrates. Annu. Rev. Ecol. Syst. 16: 339-361.

Thorson, G. 1950. Reproductive ecology of marine bottom invertebrates. Biol. Rev. 25: 1-45.

Vance, R. R. 1973. On reproductive strategies in marine bottom invertebrates. Am. Nat. 107: 353-361.

Welborn, J. R., and D. T. Manahan. 1990. Direct measurements of sugar uptake from seawater into molluscan larvae. Mar. Ecol. Prog. Ser. 65: 233-239.

Wendt, D. E., and R. M. Woollacott. 1995. Induction of larval settlement by $\mathrm{KCl}$ in three species of Bugula (Bryozoa). Invert. Biol. 114: 345-351.

Woollacott, R. M., and R. L. Zimmer. 1975. A simplified placentalike system for the transport of extraembryonic nutrients during embryogenesis of Bugula neritina. J. Morphol. 147: 355-377.

Woollazott, R. M., and R. L. Zimmer. 1978. Metamorphosis of cellularioid bryozoans. Pp. 49-63 in Settlement and Metamorphosis of Marine Invertebrate Larvae, F.-S. Chia and M. E. Rice, eds. Elsevier North-Holland, New York.

Woollacott R. M., J. A. Pechenik, and K. M. Imbalzano. 1989. Effects of duration of larval swimming period on early colony development in Bugula stolonifera (Bryozoa: Cheilostomata). Mar. Biol. 102: $57-63$.

Young, C. M., and F.-S. Chia. 1981. Laboratory evidence for delay of larval settlement in response to a dominant competitor. Int. $J$. Invertebr. Reprod. 3: 221-226.

Zimmer, R. L., and R. M. Woollacott. 1977. Metamorphosis, ancestrulae, and coloniality in bryozoan life cycles. Pp. 91-142 in Biology of Bryozoans, R. M. Woollacott and R. L. Zimmer, eds. Academic Press, New York. 